\title{
EDITORIAL
}

\section{THE 20TH IAGG WORLD CONGRESS IN SEOUL, 2013}

\author{
Heung-Bong Cha, $\mathrm{PhD}$
}

\section{Aging in Korea}

Aging is now a global challenge faced by nations in all regions of the world. The problems evoked by the continuing increase in the aged population have become critical in the East as well as in the West. Notably, Korea in East Asia is one of the fastest aging nations in the world, having exceeded the $10 \%$ aged population ratio in 2009 . We anticipate the same ratio to exceed $14 \%$ by 2018 , making Korea a truly aged society. Although Korea has attained the status of the $11^{\text {th }}$ largest economy of the world, aging is an unprecedented challenge to the nation, which needs to be met with a great deal of financial resources, professional expertise, and modern technology.

2. Issues of the aging society

The sense of urgency among Koreans on such a rapid aging trend is leading to diverse policy discussions. As the number of the older-old or the oldest-old increases drastically, the provision of eldercare, particularly long-term care, has turned to be a prominent concern of the nation. In the recent global economic downturn, how to sustain the growth of national economy has emerged as another serious issue, as the size of young and economically active population is visibly decreasing due to rapidly declining birthrates in Korea. Although Koreans still value the traditional Confucian culture of "filial piety," they are now less able to provide family-centered care for the elderly due to social changes accompanied by industrialization and urbanization. Thus, "Who will take care of the elderly and how" has emerged as a national issue. Along with this challenge, the fast aging Korean society has to reeducate or revitalize its older people to be able to adapt to and resourceful in the aging society. For this purpose, Korea has been working on an ambitious project for "digitalizing" elderly population.

3. Challenges from the digitalized world

Since the late $20^{\text {th }}$ century, the world has been moving fast toward the information-oriented society. Korea is one of the nations leading in the area of digitalization based on high-tech industry. However, due to existing barriers to digitalized information, many elderly people fall behind of other generations in utilizing information and new knowledge. Consequently, they lose out opportunities and income, and are unable to participate in social and productive activities. To prevent the marginalization of the elderly, Korea has been developing programs for the elderly to have better access to information and new knowledge by use of information technology.

4. Significance of the $20^{\text {th }}$ World Congress of the IAGG in Seoul

Facing the challenges of global aging and the increasing need for digitalization, the $20^{\text {th }}$ World Congress of the International Association of Gerontology and Geriatrics (IAGG) is slated for
2013 in Seoul. "Digital Aging: New Horizon for All Age" is the main theme chosen for the Congress, as we believe that better access to information and new knowledge can improve health and quality of life of the elderly, decrease generation gaps, and facilitate world-wide communication in the globalized social environment. We expect that researchers in biology and medicine, and in social and behavioral sciences from all over the world will present and discuss at the $20^{\text {th }}$ World Congress crosscultural, cross-generational, and interdisciplinary issues of aging referring to the digitalization of the aged along with other important problem-solving approaches.

The $20^{\text {th }}$ World Congress will be hosted by the Federation of Korean Gerontological Society (FKGS), which is an alliance of four academic organizations in gerontology and geriatrics, comprised of more than 3,000 scientists and researchers. The Korean government is fully in support of the World Congress. In addition, a number of world-class Korean corporations provide generous supports.

The $20^{\text {th }}$ World Congress is to be held as follows:

Place: The Convention and Exhibition Center (COEX) in Seoul Time: June 23 to 27 in 2013

Contact: seoul99@kornet.net

Visit: 20 th IAGG Congress Homepage (http://iagg2013.org)

\section{Seoul: the conference site}

Korea is proud of her 4,000 year history and rich traditional culture. Seoul, the capital of the nation where the Congress will be held, has rapidly developed into an energetic and lively modern city. Participants in the forthcoming Congress can experience the original Korean culture in a dynamically changing and prosperous nation where tradition is incorporated with modernity in a distinct Korean way.

Seoul ranks seventh in terms of the number of Fortune 500 multinational corporations which operate in its metropolitan area. Seoul also has branches of the world's 200 largest banks. Moreover, the metropolis is a major information center of the world; this status is reflected in the number of individuals subscribing to internet and cellular phone services, and the twenty thousand businesses related to information services clustered in the city.

You will enjoy visiting museums, historical sights, shopping centers, ethnic restaurants, and universities and research centers, which are easily accessible via the modern transportation system.

We sincerely hope all of you will be able to join us at the 20th World Congress of IAGG in Seoul. We look forward to having valuable exchanges on "Aging and Digitalization" including many other important issues of our common concern. 